\title{
Sexual Behaviour of Commercial Sex Workers and Their Clients in Cambodia
}

\author{
Shinsuke Morio ${ }^{1}$, Kenji Soda ${ }^{2}$, Kazuo Tajima ${ }^{3}$, Hor Bun Leng ${ }^{4}$, Katsuhiro Kitamura ${ }^{2}$, \\ Shunsaku Mizushima ${ }^{2}$, Kenji Ohshige ${ }^{2}$,Fengzhu Tan ${ }^{5}$, Akihiko Suyama ${ }^{5}$, \\ Heng Sopheab ${ }^{4}$, Tia Phalla ${ }^{4}$, and other members of the Japan-Cambodia Collaborating \\ Research Group
}

\begin{abstract}
Objective: This study surveyed the sexual behaviour of commercial sex workers and their clients in an attempt to identify factors of transmission of STDs (including HIV/AIDS) and to control their epidemics in Cambodia and South-East Asia.

Design: Cross-sectional study.

Setting: Trained questioners asked items of the questionnaires to each objective subject in December 1996. Data were analysed to show the descriptive status by risk group of each person.

Participants: 200 direct commercial sex workers, 220 indirect commercial sex workers, and 211 clients in Phnom Penh.

Results: Prostitution was widely accepted by both young males and females, and this was an easy way for young girls to obtain money. Although commercial sex workers and clients were knowledgeable about prevention methods against STDs, they seldom used condoms. Some commercial sex workers had been infected with STDs many times, and many of them incompletely treated the diseases by themselves. Social support from governmental and nongovernmental organisation was poor.

Conclusions: It is very important to support both commercial sex workers in practicing preventive methods against STDs and also visiting physicians when they notice symptoms of STDs. It is strongly recommended that not only governmental but also non-governmental organisations should be more active in this area.

J Epidemiol, $1999 ; 9: 175-182$
\end{abstract}

HIV, STD, commercial sex workers, sexual behaviour, South-East Asia

South-east Asia is one region where HIV/AIDS is highly epidemic ${ }^{1)}$ along with Thailand and Vietnam well-known for epidemics of HIV among commercial sex workers. Myanmar and the southern part of China is famous for an epidemic among intra-venous drug users (IVDUs). India is famous for an epidemic among both commercial sex workers and IVDUs. Cambodia, which is surrounded by these countries, is no exception. Information relating to the HIV/AIDS epidemic in Cambodia is limited ${ }^{2-5}$, although this limited information shows there has been a rapid and prevalent HIV/AIDS epidemic among the Cambodian population. The highest risk group in this country is commercial sex workers. Sentinel surveillance showed HIV sero-prevalence was about $35 \%, 25 \%, 8 \%$, and $3 \%$ among commercial sex workers, dancing girls, men who belonged to the police or military, and pregnant women, respectively ${ }^{6}$. As the epidemic among commercial sex workers is strongly related to the sexual behaviour of commercial sex workers and their clients, it is important to study the sexual behaviour of these groups in order to control the epidemic. In Cambodia, this is the first behaviour-based epidemiological study in which not only commercial sex workers but also their clients have been surveyed.

Received September 11, 1998 ; accepted November 5, 1998.

' Kochi Prefectural Tosa-shimizu Health Center, 4-5 Nishi-machi, Tosa-shimizu-shi, Kochi Prefecture, 787-0333, Japan.

2Department of Public Health, School of Medicine, Yokohama City University.

${ }^{3}$ Department of Epidemiology, Aichi Cancer Center Research Institute.

"National HIV/AIDS Programme, AIDS Office, Ministry of Health, Kingdom of Cambodia.

${ }^{5}$ Department of Hygiene, Faculty of Medicine, Tottori University.

Address for correspondence : the same as 1. 


\section{METHODS}

\section{Study Sample}

The study sample consisted of three samples, who were direct commercial sex workers, indirect commercial sex workers, and their clients in Phnom Penh, Cambodia.

\section{Direct Commercial Sex Workers (DCSWs)}

DCSWs were female commercial sex workers who were living at brothels in the red light areas of Phnom Penh. The red light districts of this study were Toul Kork Dike red light area and Trolauk Bek red light area in Toul Kork district, and Chaum Chao area in Dong Kor district. Interviewers from the National AIDS Programme, Ministry of Health interviewed DCSWs at their brothels after obtaining permission from the owners of the brothels in December 1996. No DCSWs refused the interview. Almost all DCSWs in Trolauk Bek and Chaum Chao areas were interviewed, while on the other hand, only a small number of DCSWs in Toul Kork Dike area were interviewed because of the large number of DCSWs. The numbers of interviewed DCSWs in Toul Kork Dike, Trolauk Bek, and Chaum Chao areas were 98, 56, and 46, respectively.

\section{Indirect Commercial Sex Workers (IDCSWs)}

IDCSWs were females who were working for beer companies as beer promotion girls or for massage parlors as masseuses in Phnom Penh. The beer companies were large three companies in Cambodia and the massage parlors were four parlors in the Daun Pehn and Toul Kork districts. Interviewers from the Ministry interviewed IDCSWs at their working places in December 1996 after getting permission from the managers of the companies or owners of the massage parlors. No IDCSWs refused the interview. The numbers of interviewed IDCSWs being beer promotion girls and masseuses were 190 and 30 , respectively.

\section{Clients}

Clients were males belonging to AIDS risk groups and were working in Phnom Penh, as soldiers, police-men, or were unemployed. Interviewers from the Ministry interviewed the clients at their working place or in red light areas from late December 1996 to early January 1997. As it was very difficult to interview men who were on the way to and from brothels, the clients might include men who have not had sexual contact with DCSWs or IDSCWs. The number of interviewed clients being soldiers, police-men, and unemployed men were 83 , 113 , and 15 , respectively.

\section{Questionnaires}

Three questionnaires were made for the interviews with DCSWs, IDCSWs, and clients, respectively. The questions asked were age, sex, nationality, home town, job (only for IDCSWs and clients), marriage status, sexual activities, usage of condoms, knowledge of STDs and AIDS, past history of STDs, and social support (only for DCSWs and IDCSWs). The questionnaires were made in English and translated into Khmer. Furthermore, the Kumer questionnaires were again translated into English in order to check the accuracy of the translation. The number of questions asked was 32 for DCSWs, 31 for IDCSWs, and 29 for clients. The time for the interviews was about 20 minutes. All interviewers were staff from the "National HIV/AIDS Programme, AIDS Office, Ministry of Health, Kingdom of Cambodia", and received lectures about this study and the questionnaires from a researcher of this study.

\section{Data Analysis}

Answers to the questionnaires were enclosed onto floppy disks in Cambodia and then analysed using SAS version 6.08 in Japan.

\section{RESULTS}

\section{Demographical Status}

There were many young commercial sex workers (less than 20 years old) in Phnom Penh. The mean ages of DCSWs, IDCSWs, and clients were 20.1 (minimum: 15, maximum: 34), $22.6(13,37)$, and $30.8(18,56)$, respectively (Table 1). There were 181 Cambodians and 19 Vietnamese among DCSWs, 215 Cambodians and 5 Vietnamese among IDCSWs, and 211 Cambodian clients. The home towns of 135 Cambodian DCSWs (68\%) and 174 Cambodian IDCSWs (79\%) were Phnom Penh or provinces near to Phnom Penh, respectively. Mean working duration of DCSWs and IDCSWs was 4.9 months (minimum: 1, maximum: 37 ) and 16.7 months (minimum: 1, maximum: 120), respectively. In marriage status, 197 DCSWs (99\%) and 122 IDCSWs (55\%) were single or separated females without partners. And, 136 people of the

Table 1. Mean age by DCSWs, IDCSWs and Clients (years).

\begin{tabular}{lccccc}
\hline & No. & MEAN & S.D. & MINIMUM & MAXMUM \\
\hline DCSWs & 200 & 20.1 & 3.51 & 15.0 & 34.0 \\
IDCSWs & 220 & 22.6 & 3.91 & 13.0 & 37.0 \\
Clients & 211 & 30.8 & 6.11 & 18.0 & 56.0 \\
\hline
\end{tabular}


client group $(64 \%)$ were single or married males with partners. The means of earnings and personal incomes per day for DCSWs and IDCSWs were 10.0, 4.6, 46.4, and 11.7 US dollars, respectively. Among $200 \mathrm{DCSWs}$, the reasons to choose the work (prostitution) were "to get more money" (51\%), "impossible to find other jobs" (10\%), "decision of parents/relatives/boyfriends" (7\%), and "others" (38\%). These data indicate that DCSWs are younger and poor, and change their job more frequently than IDCSWs.

\section{Sexual Activities}

A difference in sexual activities between DCSWs and IDCSWs was observed. For DCSWs, the frequency of sexual intercourse with clients per a day was higher than the number for IDCSWs, and 67 DCSWs (34\%) and 0 IDCSWs (0\%) answered that they had more than five clients a day. However, not all IDCSWs have sexual intercourse with clients every day and there were many IDCSWs who did not answer this question (Table 2). Among 211 clients, 152 (72\%) and 171 (81\%) had had sexual intercourse with commercial sex workers in the last month and in the last year, respectively. And, $9(4 \%)$ and $116(55 \%)$ of them had had sexual intercourse more than six times in the last month and in the last year, respectively. There were 56 DCSWs (28\%) and 4 IDCSWs (2\%) who answered to having sexual intercourse with foreigners, these foreign clients being Thai, Vietnamese, and Japanese. These data indicated

Table 2. Numbers of Clients per Day by DCSWs and IDCSWs.

\begin{tabular}{lcc}
\hline Client(persons) & DCSWs & IDCSWs \\
\hline $1---$ & 133 & 25 \\
$5---$ & 66 & 0 \\
$10---$ & 1 & 0 \\
Not answer & 0 & 195 \\
Total & 200 & 220 \\
\hline
\end{tabular}

that commercial sex workers are a major source of infection for STDs in Cambodia and that STDs are transmitted to foreign countries via their clients.

There were large differences in understanding and usage of condoms between DCSWs and IDCSWs. For a question of the necessity of condoms, 197 DCSWs (99\%) and 41 IDCSWs (19\%) answered that condoms were necessary for sexual intercourse with clients, and 198 DCSWs (99\%) and 18 IDCSWs $(8 \%)$ answered that they were in possession of condoms at that time, respectively. Furthermore, 125 DCSWs (63\%) and 18 IDCSWs (8\%) answered that they used condoms every time, and 29 IDCSWs (13\%) answered that they never used condoms in sexual intercourse with their clients (Table 3). Many DCSWs and IDCSWs answered that they would refuse to have sexual intercourse with clients if the clients did not use a condom. The rates of refusing were respectively, $80 \%$ and $59 \%$ of DCSWs and IDCSWs at those who answered that condoms were necessary. Among DCSWs, the most common (75\%) way of obtaining condoms was by being supplied from the owners of the brothels or hotels, and among IDCSWs, by buying them by themselves or being supplied from clients (42\%).

Incidentally, 39 clients (19\%) answered that a condom was necessary in sexual intercourse and $112(53 \%)$ answered that they used condoms every time. These data suggest that many DCSWs understand the necessity of condoms but some did not use condoms every time. It also suggests only a few IDCSWs understand the necessity of condoms and only those who had no difficulty obtaining condoms used them every time.

\section{Knowledge and Past History of STDs and AIDS}

Many of DCSWs, IDCSWs, and clients knew preventive methods against STDs (including AIDS). Respectively, 93, 96, and $94 \%$ of DCSWs, IDCSWs, and the clients answered that they had heard of preventive methods. However, the sources of knowledge about prevention differed among the groups. The three largest sources of knowledge about prevention among DCSWs were TV programs, physicians, and peer

Table 3. Status of Condom Possession, Usage and Provider by DCSWs, IDCSWs and Clients.

\begin{tabular}{|c|c|c|c|c|c|c|c|}
\hline & & \multicolumn{2}{|c|}{ DCSWs } & \multicolumn{2}{|c|}{ IDCSWs } & \multicolumn{2}{|c|}{ Clients } \\
\hline & & No. & Percent & No. & Percent & No. & Percent \\
\hline \multirow[t]{4}{*}{ Possession } & Yes & 198 & 99.0 & 18 & 8.2 & 39 & 18.5 \\
\hline & No & 1 & 0.5 & 184 & 83.6 & 164 & 77.7 \\
\hline & Not answer & 1 & 0.5 & 18 & 8.2 & 8 & 3.8 \\
\hline & Total & 200 & 100.0 & 220 & 100.0 & 211 & 100.0 \\
\hline \multirow[t]{5}{*}{ Usage } & Every time & 125 & 62.5 & 18 & 8.2 & 112 & 53.1 \\
\hline & Sometimes & 74 & 37.0 & 6 & 2.7 & 67 & 31.8 \\
\hline & Never use & 1 & 0.5 & 29 & 13.2 & 6 & 2.8 \\
\hline & Not answer & 0 & 0.0 & 167 & 75.9 & 26 & 12.3 \\
\hline & Total & 200 & 100.0 & 220 & 100.0 & 211 & 100.0 \\
\hline
\end{tabular}


education (rate: $41 \%, 30 \%$, and $29 \%$ ), among IDCSWs were TV programs, radio programs, and speaking with friends (rate: $79 \%, 40 \%$, and $10 \%$ ), and among the clients were TV programs, books/newspapers, and speaking with friends (rate: $91 \%, 46 \%$, and 19\%) . There were 169 DCSWs, 186 IDCSWs, and 204 clients, who were able to give answers concerning examples of infectious routes of STDs. Many of the given examples were sexual intercourse, blood/blood products, sharing of needles, and mother to child. However there were a few DCSWs and IDCSWs who also answered mosquito bites, kissing, or urine.

Many DCSWs and also IDCSWs had a past history of infection by STDs, and 164 DCSWs (82\%) and 70 IDCSWs (32\%) answered that they had had STDs in the past. Among these, $47 \%$ of DCSWs and $44 \%$ of IDCSWs answered that they had been infected more than twice, and $8 \%$ of DCSWs and $6 \%$ of IDCSWs answered more than five times (Table 4). The three most common STDs were vaginal discharge, gonorrhea, and genital warts. Many DCSWs and IDCSWs had been treated by physicians in public hospitals or private clinics. However,
69 DCSWs (42\%) and 19 IDCSWs (12\%) had treated themselves by purchasing drugs.

The frequency of infection by STDs was almost the same for beer promotion girls and masseuses, 53\% of the former and $50 \%$ of the later answered that they had been infected more than twice in the past. However, the length of employment was quite different with the mean length of employment for beer promotion girls and masseuses being 19 months and 7 months. The risk of infection by STDs for masseuses was greater than that for beer promotion girls.

Among the clients, there were also many who had experienced symptoms of STDs in the past. $10 \%$ and $14 \%$ of the clients had had ulcers in the genital region and urination pain/discharge respectively in the last year, and $21 \%$ and $38 \%$ respectively had had these symptoms in the past five years. Many of the clients had been treated by physicians in public hospitals or private clinics. However, 20 and 44 (46\% and $55 \%$ ) had treated their ulcers in the genital region and urination pain/discharge, respectively. These data suggest that treatment of STDs might be incomplete and that some of the infected

Table 4. Status of STD Infection and Treatment by DCSWs and IDCSWs.

\begin{tabular}{|c|c|c|c|c|c|}
\hline & & \multicolumn{2}{|c|}{ DCSWs } & \multicolumn{2}{|c|}{ IDCSWs } \\
\hline & & No. & Percent & No. & Percent \\
\hline \multirow[t]{4}{*}{ Infection of STDs } & Yes & 164 & 82.0 & 70 & 31.8 \\
\hline & No & 36 & 18.0 & 145 & 65.9 \\
\hline & Unknown & 0 & 0.0 & 5 & 2.3 \\
\hline & Total & 200 & 100.0 & 220 & 100.0 \\
\hline \multirow[t]{7}{*}{ Freq. of STDs } & Once & 79 & 48.2 & 28 & 40.0 \\
\hline & Twice & 42 & 25.6 & 15 & 21.4 \\
\hline & Three times & 12 & 7.3 & 10 & 14.3 \\
\hline & Four times & 10 & 6.1 & 2 & 2.9 \\
\hline & More than 5 times & 13 & 7.9 & 4 & 5.7 \\
\hline & Unknown & 8 & 4.9 & 11 & 15.7 \\
\hline & Total & 164 & 100.0 & 70 & 100.0 \\
\hline \multicolumn{2}{|c|}{ Kinds of infected STDs*** } & $N=164$ & Rate (\%) & $\mathrm{N}=70$ & Rate (\%) \\
\hline \multicolumn{2}{|c|}{ Syphilis } & 7 & 4.3 & 0 & 0.0 \\
\hline \multicolumn{2}{|c|}{ Gonorrhea } & 29 & 17.7 & 7 & 4.3 \\
\hline \multicolumn{2}{|c|}{ Burning during urination } & 4 & 2.4 & 0 & 0.0 \\
\hline \multicolumn{2}{|c|}{ Genital wart } & 8 & 4.9 & 0 & 0.0 \\
\hline \multicolumn{2}{|c|}{ Vaginal discharge } & 97 & 59.1 & 41 & 58.6 \\
\hline \multicolumn{2}{|c|}{ Person curing STDs*** } & $\mathrm{N}=164$ & Rate $(\%)$ & $\mathrm{N}=70$ & Rate (\%) \\
\hline \multicolumn{2}{|c|}{ Physician in public hospital } & 35 & 21.3 & 20 & 28.6 \\
\hline \multicolumn{2}{|c|}{ Physician in a private clinic } & 64 & 39.0 & 33 & 47.1 \\
\hline \multicolumn{2}{|c|}{ Pharmacist in a city } & 2 & 1.2 & 0 & 0.0 \\
\hline \multicolumn{2}{|c|}{ Traditional healer } & 0 & 0.0 & 5 & 3.0 \\
\hline \multicolumn{2}{|c|}{ By oneself with drugs } & 69 & 42.1 & 19 & 11.6 \\
\hline
\end{tabular}

\footnotetext{
***:multiple choice
} 
Table 5. Advisor to DCSWs and IDCSWs.

\begin{tabular}{lrrrrr}
\hline & \multicolumn{2}{c}{ DCSWs } & \multicolumn{2}{c}{ IDCSWs } \\
& No. & Percent & No. & Percent \\
\hline Have $\quad$ Yes & 147 & 73.5 & 167 & 75.9 \\
No & 28 & 14.0 & 37 & 16.8 \\
Not answer & 25 & 12.5 & 16 & 7.3 \\
Total & 200 & 100.0 & 220 & 100.0 \\
\hline Advisor*** & N=147 & Rate (\%) & N=167 & Rate (\%) \\
One's-own Parents & 6 & 4.1 & 85 & 50.9 \\
Husband/Boyfriend & 1 & 0.7 & 65 & 38.9 \\
Girlfriend & 38 & 25.9 & 18 & 10.8 \\
Owner of a brothel & 98 & 66.7 & 0 & 0.0 \\
Person from NGOs & 6 & 4.1 & 0 & 0.0 \\
Person in the same job & 3 & 2.0 & 1 & 0.6 \\
Medical assistant & 0 & 0.0 & 3 & 1.8 \\
Relatives & 0 & 0.0 & 4 & 2.4 \\
House/Restaurant owner & 0 & 0.0 & 2 & 1.2 \\
\hline
\end{tabular}

$* * *$ :multiple choice

clients might continue to be a source of infection.

\section{Social Support}

Advisors for DCSWs were very limited, but there were a few for IDCSWs. The advisors for many DCSWs were only the owners of their brothels (answer rate: 67\%) or their girlfriends (answer rate: $26 \%$ ), and only 6 DCSWs (4\%) answered persons from a non-governmental organisation (NGO). And, $85(51 \%), 65(39 \%)$, and 18 (11\%) IDCSWs answered their parents, their husbands/boyfriends, and their girlfriends, respectively. Furthermore, a few IDCSWs answered their relatives, medical assistants, or the owners of the place of work (Table 5). These data suggest that DCSWs do not have many advisors.

\section{DISCUSSIONS}

There are some limitation to studying sexual behaviour among commercial sex workers and clients. Firstly, it is almost impossible to get representative samples. Secondly, many interviewees are apt not to answer questions they dislike. Thirdly, many interviewees are apt to select answers that they believe the interviewer expects. This behavioural study also includes these weak points. However, AIDS epidemics among commercial sex workers in southeast Asia are very famous with about $30 \%$ of workers being HIV antibody positive ${ }^{n}$. Strong countermeasures against this epidemic are desired. In order to establish these countermeasures, sexual behavioural studies of commercial sex workers are necessary even if they include some weak points. Indeed, there have been many sexual behavioural studies among not only com- mercial sex workers but also the general population in HIV/AIDS epidemic areas ${ }^{8-13)}$.

This study showed that there are many young commercial sex workers of less than 20 years in age. In developing countries, prostitution is a bad but simple way to get money. Some developing countries in southeast Asia are famous for very young commercial sex workers ${ }^{14,15)}$. Some commercial sex workers obey their parents' decision to employ them in this work while others decide on the job by themselves. In this study, the answers to a question concerning the reason for choosing the job showed many DCSWs began the work in order to get money by themselves. Only a few DCSWs answered that their parents had decided on the job for them. The average of earnings and personal income per day for DCSWs were about 10 and 5 US dollars, respectively. This personal income value is relatively higher than that in the general population (about 50 US dollars per month) in Cambodia.

There were big differences of marriage status between DCSWs and IDCSWs in this study. Almost all DCSWs were single or separated, but about one third of IDCSWs were married and about one quater of single IDCSWs had male partners. In this study, female commercial sex workers who were living at brothels were defined as DCSWs. At the brothels, DCSWs live in small rooms, spend the day time with fellow workers, and spend night time with clients. Having boy-friends, partners, or husbands would be very difficult. The IDCSWs were beer promotion girls who advertised their company's beer at restaurants or were masseuses who worked at massage parlors. They live in their own houses or apartments and are able to have boy-friends, partners, or husbands. This difference in marriage status is strongly related to social support without 
doubt. In addition, DCSWs are females who have few trustworthy advisors.

There were also big differences in sexual activities between DCSWs and IDCSWs. Many DCSWs have to have sexual intercourse with two or more clients during the night in their small rooms of brothels. Some IDCSWs work their jobs (beer advertisement or massage) without sexual intercourse with clients and other IDCSWs have sexual intercourse after negotiation. The places of sexual intercourse for IDCSWs are hotels, their apartments or the small rooms of massage parlors. Compared to the clients of DCSWs, the clients of IDCSWs may be richer and the personal income of IDCSWs is higher than that of DCSWs. Furthermore, IDCSWs receive a salary for their work items. It may not be necessary for them to have sexual intercourse with many clients in a night. This difference in sexual activity indicates that control of STDs among DCSWs is more important than that among IDCSWs. Furthermore, due to the many styles of sexual activity in IDCSWs, control of STDs among IDCSWs is more difficult than among DCSWs.

In Cambodia, prostitution is prohibited by law, but having sexual intercourse with commercial sex workers is commonly accepted among young males ${ }^{16)}$. This study showed that many young males (soldiers, police-men, and unemployed men) frequently have sexual intercourse with commercial sex workers. They do not have sexual intercourse with IDCSWs but with DCSWs as their salary is not high enough. In Cambodia, it will be almost impossible to change the sexual attitudes of young males in the near future thus strategies preventing STDs among these males, such as safe sex, must be promoted.

Knowledge of STDs (including AIDS) was common among not only commercial sex workers but also young males, but, it is important to continue providing correct knowledge of STDs, especially for new adults. As the biggest source of their knowledge was TV programs, this is the most effective way of providing knowledge about STDs. There were also many DCSWs who answered peer education as the source of their knowledge and it is very important to promote peer education for DCSWs. Furthermore, because many DCSWs answered that the owners of the brothels were their advisors, this must strongly influence DCSWs. Education for peer educators and the owners of brothels is more practical and more useful for DCSWs who have sexual intercourse with many different clients ${ }^{17,18)}$. Some owners of the brothels were ex-commercial sex workers and were friends of present workers who are providing peer education. Compared to the wide distribution of knowledge about preventing STDs, condom usage was not very common. This indicates that commercial sex workers and young males have a general knowledge of STDs but they do not utilise this knowledge in their sex lives. There are some developing countries where distribution of condoms is the principal countermeasure against HIV/AIDS epidemic.
However, this study suggests that only distribution of condoms without promoting and supporting of utilising condoms might be almost no-effective.

The data about past history of STDs showed a miserable situation concerning commercial sex workers in Cambodia. As mentioned before, prostitution is commonly accepted, condoms are seldom used by commercial sex workers and young males, and not all STD-infected people are treated by physicians. Accordingly, it is natural that many commercial sex workers and young males suffer from STDs. Sentinel surveillance of HIV which is conducted by the National AIDS Program, Cambodian Ministry of Health also showed high HIV-positive rates among commercial sex workers, soldiers, and police-men ${ }^{6}$. In Cambodia, the leading causes of death are malaria, tuberculosis, Dengue fever, etc. with the number of deaths from STDs being small (cumulative number of deaths from AIDS was 96 in December 1996). People seem not to be afraid of STDs which include AIDS. Even if people are infected with curable STDs, they are not completely treated by medical doctors, and as AIDS is not curable, HIV-infected people are a source of infection until their death. The number of deaths from STDs will no doubt gradually increase in the near future. One report indicates that an AIDS epidemic would cause large decreases in the populations of southeast Asian countries ${ }^{19}$. It is important to continue preventive education and to establish medical supply systems for commercial sex workers and the common population. In particular, governmental medical clinics for DCSWs are urgently required and these clinics should be located at places near to the red light areas and to provide preventive peer education, free laboratory tests, and free treatment of STDs.

As mentioned before, many DCSWs and IDCSWs already had knowledge about STDs and their preventive methods. However, some of them did not use condoms and some did not visit physicians for treatment of their STDs. There were many commercial sex workers who had a past history of STDs and HIV sero-prevalence among them was high. Social support for them in the use condoms, the treatment of STDs, and to advice on their problems is very important for improving this situation ${ }^{20-22}$. This study showed social support for commercial sex workers, especially DCSWs, was poor. Social support is one of the biggest issues discussed at the international HIV/AIDS conventions ${ }^{2)}$. Many kinds of social support activities were presented at the 4th International Congress on ADS in Asia and the Pacific which was held in Manila, Philippines in 1997. However, there was no presentation of social support activities from Cambodia. The economic situation in Cambodia is poor and governmental activity for supporting commercial sex workers is very limited. Only advice for commercial sex workers at the National STD Center and a few governmental medical clinics are carried out by the Cambodian gov- 
ernment ${ }^{5}$. In other developing countries, many of the social support activities are carried out by non-governmental organisations (NGOs) ${ }^{24-26)}$. In Cambodia, especially, it is important to introduce and support non-governmental organisations. Without social support activities by NGOs, it might be impossible to control not only the HIV/AIDS epidemic but also STDs epidemic in Cambodia.

These data suggest economical development is very important for decreasing prostitution and for prevention of STDs. If there are other jobs by which young females can earn a good wage, the number of commercial sex workers will decrease, and if there are other past-times in which young males can participate, as number of clients will decrease. Economical support from developed countries is important in controlling STDs in Cambodia, even if this support does not show results which are directly related to STDs in the short term.

\section{ACKNOWLEDGMENTS}

This study was supported by a Grant-in-Aid for International Scientific Research Program from the Ministry of Education, Science, Sports and Culture, Japan (No. 07041165, FY 1995 and 1996, Chief researcher: Dr. Kenji Soda). The authors thank Dr. Georg Petersen and Dr. Annie Macarry, Cambodian Office, World Health Organization, Dr. Sophal Oum, Cambodia National Center for Hygiene and Epidemiology, Dr. Heng Sin, Cambodia National STD Center, Dr. San An, Toul Kork STD Clinic, Mr. Koji Sakane, Mr. Masatoshi Teramoto, and Ms. Aiko Nishi, Cambodian Office, Japan International Cooperation Agency for their cooperation to this study.

Members of the Japan-Cambodia Collaborating Research Group: Dr. Kenji Soda (Chief, Yokohama City University, Japan), Dr. Katsuhiro Kitamura (Yokohama City University), Dr. Shunsaku Mizushima (Yokohama City University), Dr. Kenji Ohshige (Yokohama City University), Dr. Kazuo Tajima (Aichi Cancer Center Reserch Institure, Japan), Dr. Shinsuke Morio (Tottori University, Japan), Ms. Fengzhu Tan (Tottori University), Dr. Akihiko Suyama (Tottori University), Ms. Keiko Namiki (System Science Consultants INC., Japan), Dr. Hor Bun Leng (Ministry of Health, Cambodia), Dr. Tia Phalla (Ministry of Health), Dr. Heng Sopeab (Ministry of Health), Dr. Sok Bunna (Ministry of Health), Dr. Mun Phalkun (Ministry of Health), and Ms. Ek Someth (Ministry of Health).

\section{REFERENCES}

1. Mann J, Tarantola D. Global overview. a powerful HIV/AIDS pandemic. In; Mann J, Tarantola D, eds, AIDS in the world II. New York \& London: Oxford University Press. 1996.

2. Richner B, Laurent D, Sunnarat Y, Bee D, Nadal D.
Spread of HIV-1 to children in Cambodia. Lancet, 1997; 349: 1451.

3. Soeprapto W, Ertono S, Hudoyo H, et al. HIV and peacekeeping operations in Cambodia. Lancet, 1995; 346: 1304-1305.

4. Marcus A. Cambodian blood supply trained by demand. Nat Med, 1996; 2: 1289.

5. Soda K, Morio S, Tajima K, et al. The HIV/AIDS epidemic in Cambodia. Jpn J Public Health, 1997; 44: 411418. (in Japanese with English summary)

6. Ministry of Health. Appendix. In; Kingdom of Cambodia - report on tuberculosis - 1996. Phnom Penh, Cambodia: Ministry of Health. 1996.

7. Stanecki KA, Way PO. The dynamic HIV/AIDS pandemic. In; Mann J, Tarantola D, eds, AIDS in the world II. New York \& London: Oxford University Press. 1996.

8. Rehle T, Brinkmann UK, Siraprapasiri, Coplan P, Aiemsukawat C, Ungchusak K. Risk factors of HIV-1 infection among female prostitutes in Khon Kaen, Northeast Thailand. Infection, 1992; 20: 328-331.

9. Phanuphak P, Muller O, Sarangbin S, Sittitrai W. Knowledge, attitudes and behaviour among HIV-positive and HIV-negative clients of a confidential HIV counseling and testing center in Thailand. AIDS, 1994; 8: 13151319.

10. Ward H, Day S, Mezzone J, et al. Prostitution and risk of HIV: female prostitutes in London. BMJ, 1993; 307: 356358.

11. Johnson AM, Wadsworth J, Wellings $\mathrm{K}$, Bradshaw $\mathrm{S}$, Field J. Sexual lifestyle and HIV risk. Nature, 1992; 360: 410-412.

12. DeBuono BA, Zinner SH, Daamen M, McCormack WM. Sexual behavior of college women in 1975, 1986, and 1989. N Engl J Med, 1990; 322: 821-825.

13. ACSF investigators. AIDS and sexual behaviour in France. Nature, 1992; 360: 407-409.

14. Weniger BG, Limpakarnjanarat $K$, Ungchusak $K$, et al. The epidemiology of HIV infection and AIDS in Thailand. AIDS, 1991; 5(suppl): S71-S85.

15. Abellanosa I, Nichter M. Antibiotic prophylaxis among commercial sex workers in Cebu City, Philippines. Sex Transm Dis, 1996; 23: 407-412.

16. Dunn J, Phanny S, Ann S, Sophal S, Yam L. Demographics, working practices, and AIDS awareness among commercial sex workers in Tuol Kork Dike Area, Phnom Penh, Cambodia. Cambodia Dis Bull, 1995; 6: 101-120.

17. Sakondhavat C, Werawatanakul Y, Bennett A, Kuchaisit C, Suntharapa S. Promoting condom-only brothels through solidarity and support for brothel managers. Int J STD AIDS, 1997; 8: 40-3.

18. Tiglao TV, Morisky DE, Tempongko SB, Baltazar JC, 
Detels R. A community P.A.R. approach to HIV/AIDS prevention among sex workers. Promot Educ, 1996; 3: 25-28.

19. US Bureau of the Census. In; The impact of HIV/AIDS on world population. Washington D.C., USA: US Bureau of the Census. 1994.

20. Kim N, Stanton B, Li X, Dickersin K, Galbraith J. Effectiveness of the 40 adolescent AIDS-risk reduction interventions: a quantitative review. J Adolesc Health, 1997; 20: 204-215.

21. Ford K, Wirawan DN, Fajans P, Meliawan P, MacDonald K, Thorpe L. Behavioral interventions for reduction of sexually transmitted disease/HIV transmission among female commercial sex workers and clients in Bali, Indonesia. AIDS, 1996; 10: 213-222.

22. Laga M, Alary M, Nzila N, et al. Condom promotion, sexually transmitted diseases treatment, and declining incidence of HIV-1 infection in female Zairian sex workers. Lancet, 1994; 344: 246-248.

23. O'Malley J, Nguen VK, Lee S. Nongovemmental organization. In; Mann J, Tarantola D, eds, AIDS in the world II. New York \& London: Oxford University Press. 1996.

24. Mboi N. Women and AIDS in south and South-East Asia: the challenge and the response. World Health Stat Q, 1996; 49: 94-105.

25. Amin R, Li Y. NGO-promoted women's credit program, immunization coverage, and child mortality in rural Bangladesh. Women Health, 1997; 25: 71-87.

26. Manderson L, Mark T. Empowering women: participatory approaches in women's health and development projects. Health Care Women Int, 1997; 18: 17-30. 